\title{
On ocean carbon-cycle model comparison
}

James C. Orr

To cite this article: James C. Orr (1999) On ocean carbon-cycle model comparison, Tellus B:

Chemical and Physical Meteorology, 51:2, 509-510, DOI: 10.3402/tellusb.v51i2.16334

To link to this article: https://doi.org/10.3402/tellusb.v51i2.16334

\section{(2) 1999 The Author(s). Published by Taylor \& Francis.}

\section{曲 Published online: 15 Dec 2016.}

Submit your article to this journal ๘

LIII Article views: 64

Q View related articles $\sqsubset$

Citing articles: 1 View citing articles ¿ 


\title{
On ocean carbon-cycle model comparison
}

\author{
By JAMES C. ORR, Laboratoire des Sciences du Climat et de l'Environnement, Unite Mixte de Rechereche \\ CEA-CNRS, CEA Saclay, Bat. 709-Orme des Merisiers, F-91191 Gif-sur-Yvette, Cedex France
}

(Manuscript received in final form 2 October 1998)

\section{ABSTRACT}

The Ocean Carbon-Cycle Model Intercomparison Project (OCMIP) began in 1995 and is now in its 2nd, 3-year phase. What has motivated this effort?

Ocean carbon-cycle models allow us to test our understanding of the fundamental processes which control oceanic carbon and air-sea $\mathrm{CO}_{2}$ fluxes. Such models describe the transport and redistribution of carbon in the ocean by combining fundamental notions of ocean circulation and biogeochemistry. The more complex variety of these models describe the ocean in three dimensions at the global scale, and they allow extrapolation both in space and time. Despite their complexity, predictions from such models may be biased due to necessary oversimplifications or omissions. Bias may not be a crucial issue when running extreme scenarios to provide upper and lower limits, but extreme limits are sometimes less useful than would be the best estimate from a more realistic model.

Eliminating bias is a slow process with 3-D carbon-cycle models, in part because of their intense computer time and memory requirements. Yet in the continuous loop which involves making simulations, diagnosing results and problems, then reformulating the model, it is often the latter two steps which are rate limiting. Accelerating the steps of model diagnosis (sometimes called validation) and reformulation would speed improvements in ocean carbon-cycle models and in the global carbon cycle in general. With this in mind, ocean carbon-cycle modeling groups have begun to take advantage of their recent increase in numbers (Fig. 1). They have begun working closely together, pooling resources and developing standards, to make model validation and comparison easier, more rapid, and more thorough.

Group efforts began in 1995 when the Global, Analysis, Interpretation and Modeling Task Force (GAIM) of the International Geosphere-Biosphere Programme (IGBP) initiated the Ocean Carbon-

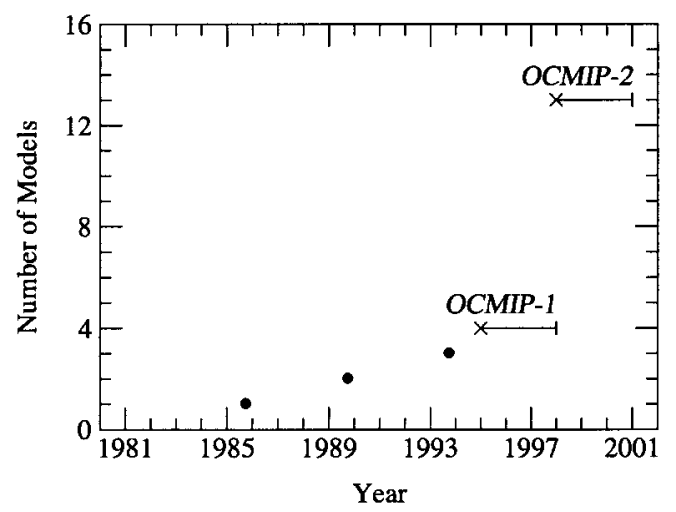

Fig. 1. The historical increase in the number of 3-D ocean models used to study of the global carbon cycle, as indicated by the number of models represented at previous International $\mathrm{CO}_{2}$ Conferences (filled circles) and those participating in the two 3-year phases of OCMIP (crosses). 
Cycle Model Intercomparison Project (OCMIP). The four modeling groups established at that time began to make standard simulations for natural and anthropogenic components of $\mathrm{CO}_{2}$ and ${ }^{14} \mathrm{C}$. Results have been compared both to available data sets (model validation) and between models (Orr, 1996). That first phase (OCMIP-1) lasted 3 years (1995-1997), the end of which was marked by the 5 th International $\mathrm{CO}_{2}$ Conference in Cairns (Orr et al., 1997a). The 2nd phase of OCMIP (1998-2000) involves 13 models and more simulations (Orr et al., 1997b). The focus remains on $\mathrm{CO}_{2}$, but OCMIP-2 also includes emphasis on new circulation tracers (e.g., CFCs), new biogeochemical tracers (e.g., $\mathrm{O}_{2}$ ), and new model validation data sets from WOCE and JGOFS..

Despite the obvious advantages of model comparison, might it not be more efficient to pursue studies with just individual models? Actually, the two approaches are complementary: model comparison is the only technique available to identify how model results differ; single model studies can address why model results differ, process by process.

Model comparison can raise important scientific questions. For example, prior to OCMIP, there were few clues as to how models compared locally. Now we see clearly that regional model differences are in many cases quite large, particularly in the Southern Ocean. Why are models estimates so different there, in a region where modeled air-sea fluxes of anthropogenic $\mathrm{CO}_{2}$ are also largest? Within OCMIP, such differences have motivated plans for OCMIP-2. Related individual model sensitivity tests are underway to help identify the major processes responsible. Elsewhere, those same OCMIP model differences appear to have heightened international interest in filling in the large data gaps in the Southern Ocean. Eventually such improved data sets will be used to better constrain ocean models.

Results from the 2nd phase of OCMIP-2 are likely to be reported at the next International $\mathrm{CO}_{2}$ Conference, to be held in Japan in the year 2001. Future work within OCMIP will probably involve coupled ocean-atmosphere models in order to study the effect of climate change on the ocean carbon cycle; validation of those simulations will focus on how well the models reproduce observed interannual variability. Those with greater interest may wish to consult progress on the OCMIP Web page http://www.ipsl.jussieu.fr/OCMIP/.

\section{Acknowledgements}

I thank P. Monfray for comments. Funding for OCMIP has been provided by the EC Environment and Climate Programme (ENV4CT95-0132 and ENV4-CT97-0495) as well as the US NSF and NASA.

\section{REFERENCES}

Orr, J. C. 1996. The ocean carbon-cycle intercomparison project of IGBP/GAIM. In: Ocean storage of carbon dioxide, workshop 3: international links and concerns (ed. Ormerod, W.). IEA Greenhouse R\&D Programme, CRE Group Ltd., Cheltenham. UK, pp. 33-52.

Orr, J. C., Sarmiento, J. L., Maier-Reimer, E., Mikolajewicz, U., Monfray, P., Palmer, J., Toggweiler, J. R., Key,
R. M., Sabine, C. L. and Gruber, N. 1997a. Anthropogenic $\mathrm{CO}_{2}$ in the ocean: 3-D models versus reality. 5th International $\mathrm{CO}_{2}$ Conference, Cairns, Australia.

Orr, J. C., Monfray, P., Sarmiento, J. L., MaierReimer, E., Palmer, J. R. and Najjar, R. G. 1997 b. Transition time for ocean carbon-cycle model comparison, Research GAIM 1, no. 2, 8-10. 